\title{
DILEMAS EM TORNO DA SOCIOEDUCAÇÃO: A EXECUÇÃO DE MEDIDAS SOCIOEDUCATIVAS EM MEIO ABERTO NO MUNICÍPIO DE ARCOVERDE, PERNAMBUCO
}

\author{
DILEMMS AROUND SOCIO-EDUCATION: \\ THE IMPLEMENTATION OF SOCIO-EDUCATIONAL MEASURES IN THE OPEN \\ ENVIRONMENT IN THE MUNICIPALITY OF ARCOVERDE, PERNAMBUCO
}

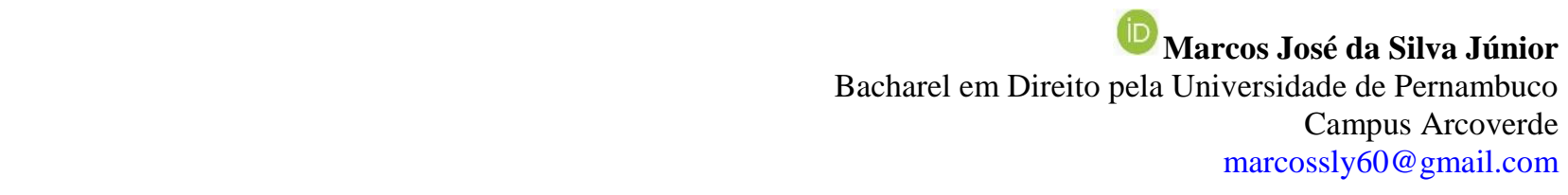

Fernando da Silva Cardoso

Doutor em Direito - Pontifícia Universidade Católica do Rio de Janeiro, com período sanduíche no Centro de Estudos Sociais da Universidade de Coimbra, Portugal. Professor Adjunto I do Curso de Direito da Universidade de Pernambuco - Campus Arcoverde cardosodh8@gmail.com

Resumo: A socioeducação surgiu com o advento do Estatuto da Criança e do Adolescente (ECA), instituído em 1990, para ser aplicada na execução das medidas socioeducativas. Como o seu conceito é algo novo e ainda em construção, sua sistematização torna-se complexa. Assim, no presente estudo são analisados os dimensionamentos da socioeducação a partir de medidas cumpridas em meio aberto no município de Arcoverde, Pernambuco. O estudo, de caráter dedutivo, de abordagem mista, é organizado a partir da coleta de dados documentais, analisados com base na técnica de análise de conteúdo. Os dados estatísticos foram extraídos de arquivos do Centro de Referência Especializado em Assistência Social (CREAS) do município de Arcoverde, Pernambuco. Os resultados apontam que no município mencionado as medidas socioeducativas cumpridas em meio aberto dimensionam o caráter pedagógico e social das atividades realizadas, inclusive para além do CREAS. No entanto, o atendimento intersetorial das ações ainda é tímido e necessita de uma melhor sistematização, a fim de que o conceito de socioeducação seja plenamente considerado na execução de tais medidas.

Palavras-chave: Medida socioeducativa. Socioeducação. Arcoverde. Pernambuco.

Abstract: Socio-education emerged with the advent of the Child and Adolescent Statute (ECA), instituted in 1990, to be applied in the execution of socio-educational measures. As its concept is something new and still under construction, its systematization becomes complex. Thus, at present study the dimensions of socio-education present are analyzed from measures carried out in the open environment in the municipality of Arcoverde, Pernambuco. The study, of deductive character, of mixed approach, is organized from the collection of documentary data, analyzed based on the technique of content analysis. The statistical data were extracted from archives of the Specialized Reference Center for Social Assistance (CREAS) in the municipality of Arcoverde, Pernambuco. The results show that in the municipality mentioned, the socio-educational measures carried out in an open environment dimension the pedagogical and social character of the activities carried out, including beyond CREAS. However, the intersectoral service of the actions is still timid and needs a better systematization, so that the concept of socio-education is fully considered in the execution of such measures.

Keywords: Socio-educational measure. Socioeducation. Green arch. Pernambuco.

\section{Para citar este artigo}

ABNT NBR 6023:2018

SILVA JUNIOR, Marcos José da; CARDOSO, Fernando da Silva. Dilemas em torno da socioeducação: a execução de medidas socioeducativas em meio aberto no município de Arcoverde, Pernambuco. Prisma Jurídico, São Paulo, v. 19, n. 1, p. 95-118, jan./jun. 2020. http://doi.org/10.5585/prismaj.v19n1.14273. 


\section{Introdução}

O Estatuto da Criança e do Adolescente trouxe para o ordenamento jurídico brasileiro o termo "medidas socioeducativas", as quais são aplicadas aos adolescentes, entre 12 e 18 anos, autores de atos infracionais. Os adolescentes não sofrem as sanções penais contidas no Código Penal Brasileiro devido ao fato de ser reconhecida sua condição peculiar de pessoa em desenvolvimento biopsicossocial. Como um reforço para o ECA, foi criada a Lei ${ }^{\circ} 12.594$ de 2012, que instituiu o Sistema Nacional de Atendimento Socioeducativo (SINASE), regulamentando a execução das medidas socioeducativas.

A Lei do SINASE aduz, no $\S 2^{\circ}$ do art. $1^{\circ}$, que as medidas socioeducativas têm como principais objetivos a responsabilização do adolescente, sua integração social, garantia de seus direitos individuais e sociais e a desaprovação da conduta infracional (BRASIL, 2012). No entanto, nem o ECA e nem a Lei do SINASE trazem um conceito instrumental de socioeducação, a fim de que as práticas no atendimento socioeducativo sejam capazes de satisfazer os objetivos das medidas. Portanto, devido ao fato de o tema da socioeducação estar permeado por uma forte imprecisão conceitual, as práticas socioeducativas acabam sofrendo desdobramentos negativos.

O Estatuto da Criança e do Adolescente tem a Doutrina da Proteção Integral como um de seus elementos orientadores. Tal doutrina prevê que tanto a criança como o adolescente devem ser tratados como sujeitos de direitos, deixando de serem vistos, dessa forma, como simples objetos de intervenção. Com isso, os adolescentes autores de atos infracionais precisam ser responsabilizados, mas também necessitam de acompanhamento pedagógico e interdisciplinar, no intuito de que as medidas socioeducativas e, consequentemente, os socioeducadores não sejam meros agentes que policiam esses jovens e enxerguem apenas o lado sancionatório das medidas.

As principais controvérsias existentes na execução das medidas socioeducativas devido à imprecisão do conceito de socioeducação são: a capacitação dos profissionais envolvidos, a inexistência de um atendimento em rede, a harmonização entre o caráter punitivo e educativo e a incompletude das instituições públicas que as implementam. Dessa forma, torna-se evidente que a delimitação do conceito de socioeducação é basilar para conferir maior clareza e intencionalidade às medidas socioeducativas. Sendo assim, o presente estudo tem o seguinte problema de pesquisa: quais os dimensionamentos da socioeducação na execução de medidas socioeducativas em meio aberto no município de Arcoverde/PE? 
Nesse contexto, a presente pesquisa tem como objetivos específicos compreender o conceito de socioeducação na perspectiva do ECA, discutir o caráter punitivo e o pedagógico das medidas socioeducativas aplicadas em meio aberto, no âmbito da Doutrina da Proteção Integral e identificar as dificuldades de implementação de práticas socioeducativas intersetoriais em meio aberto. $\mathrm{O}$ trabalho tem como foco específico as medidas socioeducativas executadas em meio aberto, pois estas têm um maior âmbito de aplicação, devido ao fato de os adolescentes autores de atos infracionais ainda estarem em convívio com a sociedade e, também, por essas medidas serem o meio de transição entre a internação e a liberdade.

A pesquisa apresenta relevância acadêmica por ressaltar o tema da socioeducação nas medidas socioeducativas em meio aberto como centro das discussões jurídicas e sociais, a fim de instigar o debate sobre o assunto, fazendo com que ele não seja deixado em segundo plano e para que deixe de ser visto com o semblante da utopia, ou seja, sem solução ou eficácia. Terá como objetivo, também, fomentar mais desdobramentos sobre a temática, tornando-a mais ampla e deixando-a em contato com diversas disciplinas.

Já existem alguns trabalhos questionando se o conceito de socioeducação é realmente aplicado nas medidas socioeducativas, mas a originalidade deste estudo, que lhe atribui relevância social, é o fato de que será estudada a realidade do município de Arcoverde/PE. Ou seja, poderá ajudar os profissionais que estejam envolvidos com o tema a tentarem melhorar ainda mais a aplicação das medidas socioeducativas em meio aberto.

\section{0 conceito de socioeducação na perspectiva do Estatuto da Criança e do Adolescente}

Hoje, a educação esforça-se para construir uma personalidade autônoma, mas em consonância com o convívio social, pois, de acordo com Jean Piajet, o objetivo da educação é formar pessoas críticas e ativas, sempre em busca da construção da autonomia, que significa a aptidão de cooperativamente construir regras necessárias à manutenção de relações centradas no respeito mútuo. A concepção de educação de Paulo Freire considera as pessoas como seres autônomos, visto que, para ele, educar é construir, é libertar o indivíduo do determinismo a fim de que ele seja capaz de transformar o mundo (ZACHARIAS, 2007 apud VIANNA, 2006).

O termo 'socioeducação' surgiu com o advento do Estatuto da Criança e do Adolescente (ECA), instituído pela Lei n 8.069 em julho de 1990. No entanto, o referido diploma não trouxe nenhuma formulação teórica sobre a concepção de socioeducação, a 
função e a finalidade das medidas socioeducativas. Em 2006, com a Resolução n ${ }^{\circ} 106$ do Conselho Nacional da Criança e do Adolescente (CONANDA) e, posteriormente, em 2012 com a Lei do Sistema Nacional de Atendimento Socioeducativo (SINASE), esforços foram feitos com o intuito de esclarecer as bases e os princípios das medidas socioeducativas. Esses dispositivos são o direcionamento organizacional para as instituições de atendimento sem serem, porém, fontes teóricas sobre a socioeducação (RANIERE, 2014).

Este obstáculo conceitual é o maior entrave para o pleno desenvolvimento das medidas socioeducativas. É a ausência de fundamentos epistemológicos, de uma formulação teórica sobre a atividade socioeducativa eminentemente pedagógica, que não seja importada de outras práticas educacionais, que incide no caráter unicamente coercitivo ou sancionatório. Tais deficiências prejudicam a prática socioeducativa, fazendo com que muitos socioeducadores sejam apenas 'seguranças' que policiam adolescentes, sem exercerem a função educativa (PAES; AMORIM, 2008).

Foi o pedagogo Antônio Carlos Gomes da Costa, um dos redatores do Estatuto da Criança e do Adolescente (ECA), que cunhou o termo "socioeducação" com o objetivo de evidenciar o caráter educativo das medidas, em detrimento da perspectiva punitiva. Para ele, a educação social possui duas vertentes, uma protetiva e outra socioeducativa. A primeira, de caráter protetivo, é voltada a crianças, adolescentes e adultos que tiveram seus direitos violados, por ação ou omissão da família, da sociedade ou do Estado ou, ainda, por sua própria conduta. A vertente socioeducativa é direcionada especificamente a adolescentes autores de atos infracionais (COSTA, 2006).

Nesse aspecto, o papel da socioeducação é preparar tal público para o convívio social e tal objetivo só será viabilizado se for dada ao jovem a oportunidade de trilhar um caminho de desenvolvimento pessoal e social interligado ao reforço de sua identidade, autoestima, autoconceito, autoconfiança, visão positiva do futuro, do querer-ser, com projeto de vida, sentido da vida, autodeterminação, resiliência, autorrealização e plenitude humana. Assim, a socioeducação é o conjunto de práticas voltadas para a realização dessas etapas e, em síntese

[...] as ações educativas devem exercer uma influência edificante na vida do adolescente, criando condições para que ele cumpra duas tarefas bem peculiares dessa fase de sua vida: i) plasmar sua identidade, buscando compreender-se e aceitar-se; ii) construir seu projeto de vida, definindo e trilhando caminhos para assumir um lugar na sociedade e um papel na dinâmica sociocomunitária em que está inserido. (COSTA, 2006, p. 57).

Portanto, a socioeducação é uma educação diferenciada, que tem como base uma epistemologia diversa da educação tradicional e dá ênfase à dimensão social, com o objetivo 
de promover as potencialidades e a autonomia do adolescente com o fortalecimento de princípios éticos. A socioeducação é educação sistemática que interfere na educação assistemática (ao longo do cumprimento de medida socioeducativa) e, com isso, conduz a ações que atendem o caráter pedagógico das medidas. Nesse sentido, segundo Barbosa (2013), os espaços de execução das medidas socioeducativas não devem ter humilhação, interdição da palavra e negação da humanidade. Pelo contrário, devem ser lugares de aprendizado da responsabilidade pessoal e social, a partir de uma pedagogia fundamentada na justiça e na inclusão.

2.1 O caráter punitivo e o pedagógico das medidas socioeducativas aplicadas em meio aberto, sob a ótica da Doutrina da Proteção Integral

O conceito de medidas em meio aberto é anterior ao próprio ECA. Essa ideia decorre das denominadas "penas alternativas" contidas no sistema prisional adulto. Em 1927, o primeiro Código de Menores indicava o atendimento em meio aberto como liberdade vigiada (BRITO, 2007). A semiliberdade estava presente no sistema penal juvenil introduzido pela Fundação Nacional de Bem Estar do Menor (FUNABEM). A medida de Liberdade Assistida foi instituída pelo Código de 1979, e a medida de Prestação de Serviços à Comunidade só surgiu com o ECA. Contudo, é com o SINASE (BRASIL, 2006; 2012) que acontece a priorização das medidas de Liberdade Assistida (LA) e de Prestação de Serviços à Comunidade (PSC):

[...] priorizou-se as medidas em meio aberto (prestação de serviço à comunidade e liberdade assistida) em detrimento das restritivas de liberdade (semiliberdade e internação em estabelecimento educacional, haja vista que estas somente devem ser aplicadas em caráter de excepcionalidade e brevidade (BRASIL, 2006, p. 14).

As medidas de Liberdade Assistida e de Prestação de Serviços à Comunidade situam o município como o ente responsável pela execução, com o apoio do Poder Judiciário e demais órgãos responsáveis pela Política de atendimento à Criança e ao Adolescente. De acordo com o SINASE (2006), é de competência do Poder Judiciário a aplicação, o acompanhamento e a supervisão das medidas socioeducativas em meio aberto e ao Órgão Executor Municipal compete o gerenciamento e o desenvolvimento das ações. Dessa maneira, os programas de execução das medidas têm como objetivo maior a construção de um projeto que, de modo constante, amplie e fortaleça os vínculos familiares e sociais, fomentando a permanência e incentivando o retorno escolar, bem como a profissionalização desse grupo (BRASIL, 2006). 
Para a operacionalização das medidas em meio aberto e $\mathrm{o}$ atendimento às particularidades de cada adolescente, faz-se necessário a elaboração do Plano Individual de Atendimento (PIA), que deve ser elaborado em conjunto com o Órgão Executor Municipal, o adolescente e sua família. Este documento tem a finalidade de registrar, de acordo com as necessidades e interesses individuais do adolescente, os objetivos e metas a serem alcançados no decorrer do cumprimento das medidas (BRASIL, 2012).

Portanto, as medidas socioeducativas em meio aberto (LA e PSC) têm por finalidade prover atenção socioassistencial e acompanhamento aos adolescestes em cumprimento de tais medidas, contribuindo para o acesso a direitos e com a reformulação de valores.

O Estatuto da Criança e do Adolescente e, consequentemente, a Lei do SINASE têm como fundamento para aplicação das medidas socioeducativas a Doutrina da Proteção Integral, a qual quebra com a ideia de que estes seriam meros objetos de intervenção. Tal doutrina surgiu na Convenção Internacional dos Direitos da Criança e do Adolescente, de 1989. Desde então o Brasil vem situou o segmento infanto-juvenil como prioridade na elaboração de políticas.

A regra básica que traz a Convenção é que a criança e o adolescente devem ter todos os direitos que têm os adultos e que sejam aplicáveis a sua idade. Além disso, devem contar, ainda, com direitos especiais decorrentes de sua caracterização como pessoa em condição peculiar de desenvolvimento pessoal e social - isso encarna a Doutrina da Proteção Integral. (PAES; AMORIM; PEDROSSIAN, 2010, p. 58).

Antes do ECA vigorava o Código de Menores, o qual tinha como fundamento a Doutrina da Situação Irregular. Nessa doutrina apenas crianças e adolescentes em situação de grande vulnerabilidade social tinham atenção do Estado. Em instituições de privação de liberdade conviviam crianças em diversos quadros: que praticavam alguma infração penal, com transtornos psíquicos ou em situação de abandono. Após o ECA, com a Doutrina da Proteção Integral, a cidadania da criança e do adolescente passa a ser regra, não sendo apenas objetos de mera tutela do Estado, da sociedade e da família.

Com a Constituição Federal de 1988 e do ECA, crianças e adolescentes passam a ser considerados sujeitos de direitos. Além dos direitos fundamentais relativos a toda pessoa, são portadores de direitos especiais em razão da sua condição peculiar de pessoa em desenvolvimento. Ao se conceber crianças e adolescentes como sujeitos de direitos e a defesa da existência de uma cidadania especial para tais sujeitos, busca-se estabelecer um contraponto à noção de que crianças e adolescentes são meros objetos de intervenção. (PAES; AMORIM; PEDROSSIAN, 2010, p. 13).

As medidas socioeducativas devem ser baseadas na Doutrina da Proteção Integral. O artigo $1^{\circ}, \S 2^{\circ}$ da Lei do SINASE indica os objetivos de tais medidas, quais sejam: a 
responsabilização do adolescente, sua integração social, a garantia de direitos e a desaprovação da conduta infracional (BRASIL, 2012). Como se vê, as medidas socioeducativas (sobretudo as aplicadas em meio aberto) não devem ter viés unicamente punitivo. Não se trata de excluir o caráter sancionatório das medidas, mas sim de acatar a existência desta dimensão que deve atuar em conjunto com um projeto pedagógico.

Costa (2006) afirma que as medidas socioeducativas têm conteúdo predominantemente pedagógico, no entanto, sua natureza é sancionatória. Isso porque a medida é imposta em resposta à infração praticada e por decorrer de uma decisão judicial. Todavia, para que o viés pedagógico seja predominante é necessário compreender as bases teóricas da socioeducação, a fim de que suas metodologias sejam consideradas quando do atendimento socioeducativo:

\begin{abstract}
A ausência de base teórica influencia na percepção da intencionalidade da metodologia de atendimento socioeducativo, na trajetória da formação inicial e continuada dos socioeducadores o que desarticula o trabalho desses profissionais formados em diferentes instituições e áreas do conhecimento. Dessa maneira, sem um fundamento teórico e metodológico consistente, os socioeducadores possuem dificuldade em exercer sua função educativa e são levados a escolherem práticas meramente coercitivas e sancionatórias. (ZANELLA, 2011, p. 65-66).
\end{abstract}

Diante desse impasse teórico-metodológico da socioeducação, propondo que o caráter pedagógico se sobressaia na execução dessas medidas, a aplicação da Pedagogia da Presença (COSTA, 2006) pode significar um elemento inovador neste quadro. Este campo considera o vínculo entre as bases teóricas e a prática socioeducativa. $\mathrm{Na}$ abordagem da Pedagogia da Presença a teoria alimenta a prática e vice-versa. Não é dada ênfase apenas à perspectiva teórica da socioeducação (cunho idealista), busca-se otimizar a prática e os métodos a fim de que estes gerem insumos para a produção de conhecimentos outros, ou seja, teorizar a prática e praticar a teoria (COSTA, 2006).

Tal Pedagogia exprime a fuga à padronização, às respostas automatizadas. Significa pensar uma prática calorosa e empática. Todavia, o objetivo deste método não é ressocializar (palavra despida de sentido pedagógico), mas sim permitir que o(a) adolescente tenha a possibilidade de socialização. A obtenção de êxito desta tarefa depende de uma ágil inteligência, do instante, uma combinação entre senso prático e teoria (COSTA, 2015). A partir da Pedagogia da Presença a principal meta é abordar as dimensões humanas, no que se refere aos impasses e dificuldades existenciais do adolescente, bem como suas atitudes diante da vida. 


\title{
2.2 A (não) implementação de práticas socioeducativas intersetoriais em meio aberto
}

A Lei $n^{\circ}$ 12.594/2012, Lei do SINASE, regulamenta a execução das medidas socioeducativas. Estipula que as políticas sociais destinadas a adolescentes autores(as) de atos infracionais devem se dar de modo intersetorial, atendendo as demandas multidisciplinares e observando a situação peculiar de pessoa em desenvolvimento biopsicossocial desse grupo. No artigo $8^{\circ}$ da referida lei é previsto que o plano de atendimento socioeducativo deverá ter “ações articuladas nas áreas de educação, saúde, assistência social, cultura, capacitação para o trabalho e esporte, para os adolescentes atendidos" (BRASIL, 2012).

Um dos princípios norteadores desse objetivo de atendimento intersetorial é o da incompletude institucional, que enfatiza a necessidade de ações articuladas, da participação dos(as) adolescentes infratores(as) em programas governamentais e não governamentais, com a máxima utilização de serviços da comunidade.

\begin{abstract}
Destacamos a incompletude institucional como um princípio que revela a proposta da política de atendimento prescrita no ECA, quanto à organização articulada que deverá existir entre ações governamentais e não-governamentais. O princípio refere que a aplicação da medida socioeducativa deverá operar dentro desta organização da rede de atendimento de forma integrada. (NEVES, 2014, p. 90-91).
\end{abstract}

Nesse sentido, para que haja o pleno atendimento socioeducativo é necessário ultrapassar o conceito de instituições totais, que remete à ideia de que uma única instituição é capaz de responder a todas as necessidades dos(as) adolescentes que cumprem medidas em meio aberto. As necessidades do atendimento socioeducativo, portanto, devem ser supridas através da articulação entre os órgãos municipais que têm interesses em comum na efetivação dos direitos desse grupo, através de políticas públicas de educação, saúde, assistência social, cultura, esporte, segurança pública e justiça (PAES; ADIMARI; COSTA, 2015).

Em consonância com a ideia da intersetorialidade, o ECA dispõe o Sistema de Garantia de Direitos (SGD). Este Sistema articula a efetivação da Doutrina da Proteção Integral. É elemento de interpretação sistêmica do ECA e visa a articulação e a integração das políticas governamentais e da sociedade civil voltadas para a promoção e defesa dos direitos das crianças e dos adolescentes. O artigo 86 do ECA, nesse sentido, afirma que os direitos desses grupos devem ser articulados, ou seja, em oposição ao modelo centralizado e vertical que existia na vigência da Doutrina da Situação Irregular (JULIÃO; OLIVEIRA; GODOI, 2017).

Para os(as) adolescente em conflito com a lei, o Sistema de Garantias de Direitos (SGD) é formado por diversos subsistemas, quais sejam: Sistema Educacional, Sistema de 
Justiça e Segurança Pública, Sistema Único de Saúde, Sistema Único de Assistência Social e Sistema Nacional de Atendimento Socioeducativo. O SINASE é o subsistema específico que se molda às influências desses demais subsistemas, com a finalidade de garantir os princípios da incompletude institucional e da doutrina da proteção integral. Dimensiona o atendimento em rede para a inclusão social de adolescentes que cumprem medidas socioeducativas.

A Lei do SINASE, em seu artigo $5^{\circ}$, inciso III, juntamente com o artigo 88, inciso I, do ECA, afirma que compete aos municípios executar as medidas socioeducativas de meio aberto de Liberdade Assistida e de Prestação de Serviços à Comunidade (BRASIL, 1990; 2012). A municipalização pelo fato dessas medidas manterem o(a) adolescente em seu convívio social, fortalecendo vínculos familiares e comunitários, efetivando a sua inserção na rede de serviços públicos. Para que o objetivo da intersetorialidade seja efetivado, deve ser elaborado o Plano Individual de Atendimento (PIA) para cada adolescente infrator(a), instrumento utilizado para excluir a homogeneização excludente do atendimento.

Contudo, para que o PIA possa ser executado plenamente, é importante a existência e aplicabilidade de outro instrumento de gestão do atendimento socioeducativo intersetorial, qual seja: o Plano Municipal de Atendimento Socioeducativo. De acordo com o SINASE, este Plano deve estar em conformidade com o Plano Estadual e o Plano Nacional de Atendimento Socioeducativo. Assim, o Plano Nacional deve incluir o diagnóstico da situação do SINASE, as diretrizes, os objetivos, as metas, as prioridades e as formas de financiamento e gestão das ações de atendimento para os dez anos seguintes. O Plano Nacional de Atendimento Socioeducativo (2013-2022), de 2013, prevê quatro eixos de ação: gestão do SINASE, qualificação do atendimento socioeducativo, participação e autonomia dos adolescentes, fortalecimento dos sistemas de justiça e segurança pública. Os Planos Estaduais ${ }^{1}$ e Municipais também são decenais e precisam prever, necessariamente, a articulação com os demais órgãos das áreas de educação, saúde, assistência social, cultura, trabalho e esporte, a fim de organizar a execução das medidas e o percurso formativo dos(as) adolescentes (BRASIL, 2012).

Assim, os planos de atendimento socioeducativo são referências para a atuação da Comissão Intersetorial de Atendimento Socioeducativo, que se constitui em uma instância responsável pela estruturação, elaboração e acompanhamento das ações intersetoriais presentes nos planos. O Plano Nacional de Atendimento Socioeducativo prevê a criação dessa comissão intersetorial em cada Estado, no Distrito Federal e nos Municípios, que deve ser

\footnotetext{
${ }^{1}$ O Plano Decenal de Atendimento Socioeducativo do Estado de Pernambuco foi elaborado e abrange o período de execução de 2015 a 2024. No entanto, nem todos os municípios do estado construíram seus planos de atendimento, o que compromete a boa execução das medidas de socioeducação, principalmente as de meio aberto, visto que elas são de competência direta dos municípios.
} 
composta por representantes de todas as políticas setoriais e instituições da rede de socioeducação. As ações da comissão intersetorial têm como objetivo a divisão das responsabilidades e a promoção das transversalidades das políticas intersetoriais do SINASE (MDS, 2016).

É inegável que as mudanças no ordenamento jurídico voltado para o público infantojuvenil trouxeram avanços para o atendimento socioeducativo. No entanto, a implementação dos princípios referidos ainda é efetiva, visto que as ações intersetoriais ainda são pontuais e fragmentadas, não sendo, dessa maneira, um projeto comum e que acarreta a corresponsabilização dos órgãos (JULIÃO; OLIVEIRA; GODOI, 2017). A execução das medidas em meio aberto realizada de forma intersetorial e interdisciplinar é, certamente, o maior desafio à aplicabilidade socioeducação.

\section{0 trajeto metodológico da pesquisa}

O universo da pesquisa compreende as informações fornecidas pelo Centro de Referência Especializado de Assistência Social (CREAS) do município de Arcoverde, Pernambuco, sobre adolescentes que cumpriram medidas socioeducativas de liberdade assistida e de prestação de serviços à comunidade no município, entre os anos de 2015 e $2018^{2}$. As informações compõem os arquivos produzidos pelos educadores(as) sociais.

O método de pesquisa utilizado foi o dedutivo (LAKATOS; MARCONI, 2003). A partir da coleta de dados feita no CREAS do referido município foi observado como as medidas socioeducativas em meio aberto (LA e PSC) são aplicadas, verificando se, porventura, têm caráter punitivo ou pedagógico, se o município possui certa organização do atendimento socioeducativo intersetorial e, por fim, se o conceito de socioeducação é presente na aplicação das medidas. Nesse sentido, os fenômenos observados foram classificados e, em seguida, feitas as correlações entre eles, a fim de se chegar a premissas sobre os dimensionamentos socioeducacionais envolvidos nas medidas aplicadas no município em questão.

O estudo é de abordagem mista, visto que a construção de sentidos e significados sobre o objeto de pesquisa foi organizada a partir de sua dimensão quali e quantitativa, visando o conhecimento aprofundado do universo eleito. Ou seja, dados estatísticos e análises

\footnotetext{
${ }^{2}$ Como este estudo foi elaborado ainda no primeiro semestre do ano de 2019, este ano não foi considerado na pesquisa pois, na formulação dos dados estatísticos, foram utilizados apenas anos completos.
} 
qualitativas ajudaram a evidenciar aspectos relevantes dos dados (LAKATOS; MARCONI, 2003).

A técnica de coleta de dados utilizada foi a pesquisa documental. A partir de arquivos públicos do município de Arcoverde e de relatórios elaborados. A pesquisa documental foi realizada através de documentos autênticos, contemporâneos ou retrospectivos, buscando descrever ou comparar fatos sociais, formulando premissas. A pesquisa bibliográfica em obras contribuiu com a fundamentação dos argumentos (GERHARDT; SILVEIRA, 2009).

A técnica de análise de dados utilizada foi a análise de conteúdo, pois esta possibilitou a leitura (qualitativa e quantitativa) das informações coletadas. Dessa forma, buscou-se a descrição do conteúdo dos indicadores para se chegar a uma série de significações. A técnica compreendeu a leitura dos relatórios e demais documentos, relacionando as estruturas semânticas e os enunciados principais (GERHARDT; SILVEIRA, 2009).

\subsection{Os marcadores sociais dos(as) adolescentes que cumprem medidas socioeducativas em meio aberto no CREAS do município de Arcoverde, Pernambuco}

Não foi objetivo do estudo traçar os caminhos ou motivos que levaram os(as) adolescentes a cometerem atos infracionais. Entretanto, é necessário destacar os marcadores sociais deste grupo que cumpre as medidas socioeducativas em meio aberto devido ao fato de serem elemento (subjetivo e central) da socioeducação. Para tanto, são apresentados dados de âmbito nacional e, em seguida, feita a correlação com os dados do município de Arcoverde/PE. Entretanto, é válido ressaltar que existem poucos dados estatísticos no Brasil sobre adolescentes em cumprimento de medidas socioeducativas em meio aberto. O relatório anual do SINASE traz dados apenas de adolescente em cumprimento das medidas de internação e semiliberdade.

O Ministério do Desenvolvimento Social (MDS) realizou uma pesquisa de âmbito nacional, no ano de 2018, para conhecer o perfil das medidas socioeducativas em meio aberto e o perfil de adolescentes que as cumprem. O relatório da pesquisa indicou que $89 \%$ dos(as) adolescentes são do sexo masculino e $11 \%$ são do sexo feminino, $82 \%$ estão na faixa etária dos 16 aos 21 anos (MDS, 2018). Já no município de Arcoverde, Pernambuco, em comparação com os dados nacionais dos adolescentes em cumprimento das medidas socioeducativas em meio aberto, tem-se as seguintes estatísticas e marcadores sociais: 
Gráfico 1 - Gênero dos adolescentes que cumpriram medidas socioeducativas em meio aberto no município de Arcoverde/PE nos anos de 2015 a 2018

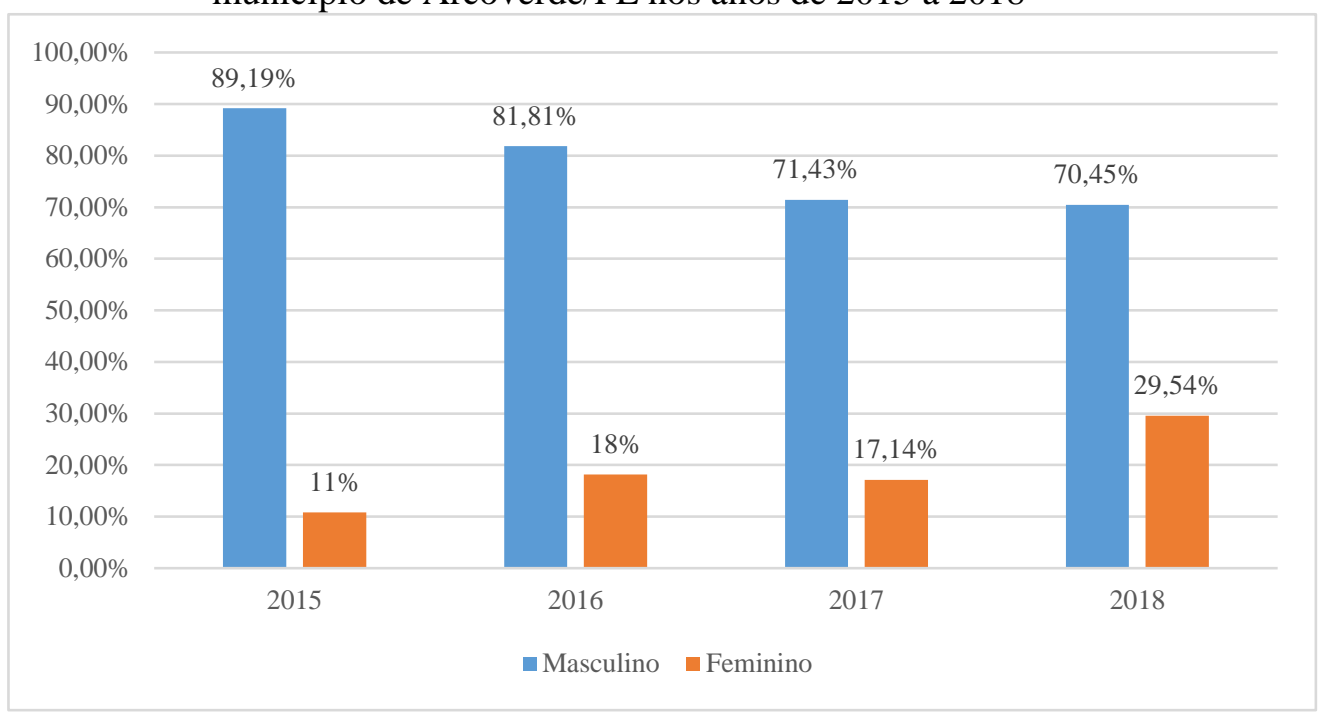

Fonte: Dados coletados pelos autores.

O Gráfico 1 demonstra que existe certa prevalência de adolescentes do sexo masculino no cumprimento das medidas socioedutivas em meio aberto. Todavia, verifica-se que a cada ano a porcentagem de adolescentes do sexo feminino neste tipo de medida tem aumentado. A mudança de panorama que está acontecendo no período mencionado precisa ser mais bem analisada. O complexo fenômeno merece atenção tanto quanto à masculinização do quadro, quanto sobre o aumento da presença de adolescentes do sexo feminino, o que denota um novo cenário para o atendimento socioeducativo, como cita Aranzedo (2015). Em suma, as adolescentes que praticam ato infracional são vistas como menos ofensivas à sociedade. Suas estratégias de sobrevivência são brandas devido ao sistema machista que as colocam (duplamente) em situação de vulnerabilidade e submissão. O número maior de adolescentes do sexo masculino se dá, a nosso ver, pelo fato de estes serem cooptados de forma mais direta pela criminalidade juvenil (ANDRADE; CARDOSO, 2018; MACHADO, 2010).

O Gráfico 2 aponta que aproximadamente metade e, em alguns anos, menos que a metade, dos adolescentes que cumpriram medidas socioeducativas em meio aberto no referido município estavam frequentando a escola. 
Gráfico 2 - Adolescentes que estavam cumprindo medidas socioeducativas em meio aberto no município de Arcoverde/PE e frequentavam a escola nos anos de 2015 a 2018

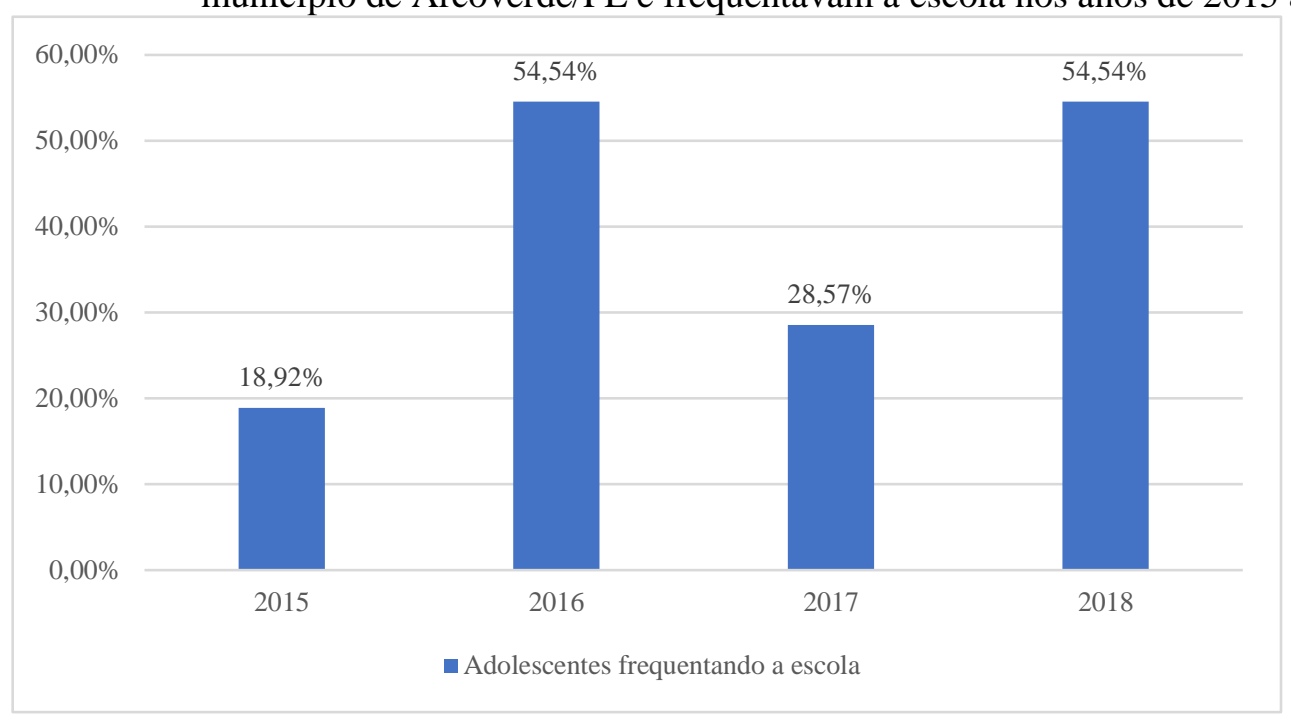

Fonte: Dados coletados pelos autores.

Observamos, por outro lado, nos relatórios, que as taxas de escolarização estão, em alguma medida, relacionadas com os delitos praticados. Constatou-se que a equipe técnica do CREAS estudado incentiva os(as) adolescentes a retornarem os estudos, solicitando, sobretudo, o refazimento de suas matrículas escolares. Viu-se igualmente, que o retorno aos estudos encontra obstáculos nas próprias escolas. Há certo número de matrículas negadas, apesar da ser vedada tal postura, o que ressalta o preconceito e o estigma com adolescentes que cumprem medida socioeducativa. O estigma do 'menor infrator' ainda é evidente.

Portanto, o estigma para com quem infringe a lei gera uma expectativa de que, a qualquer momento, os(as) jovens voltarão a criar alguma desordem, sendo um problema social e escolar. As linhas das regras tornam-se menos flexíveis e, caso algo fora do comum aconteça, não se considera mais apenas como um ato de indisciplina, mais sim como um reforço da ideia de quem tem uma conduta 'infratora' e, até certo ponto, criminosa.

O Gráfico 3 mostra que, no município de Arcoverde, Pernambuco, entre os anos de 2015 e 2018, houve uma diminuição significativa no percentual de adolescentes que cumpriram medidas socioeducativas em meio aberto e que afirmavam fazer uso de drogas. 
Gráfico 3 - Adolescentes cumprindo medidas socioeducativas em meio aberto no município de Arcoverde/PE que relataram usar drogas, entre os anos de 2015 e 2018

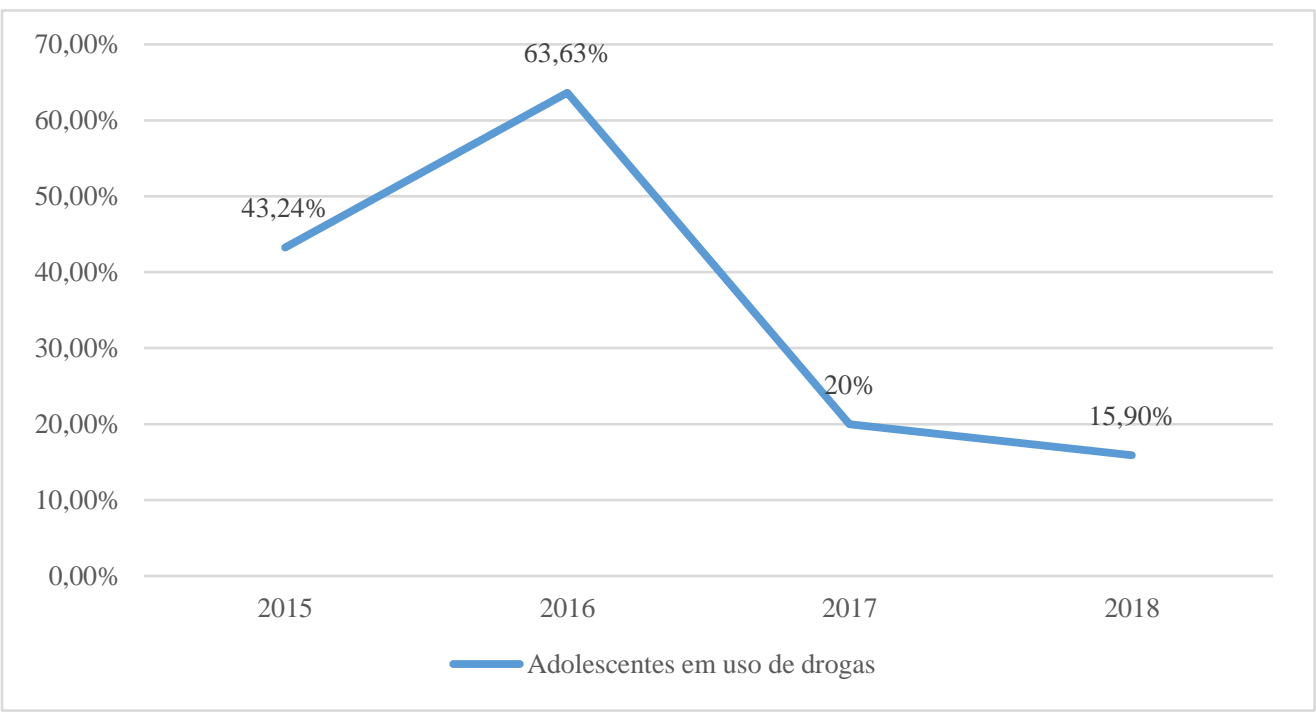

Fonte: Dados coletados pelos autores.

Vê-se que, mesmo havendo uma diminuição dos percentuais, ainda é elevado o número de adolescentes que cumprem medidas socioeducativas em meio aberto e que utilizam drogas, ressaltando alguma correlação entre o processo de drogadição e a prática de atos infracionais.

\subsection{O cumprimento de medidas em meio aberto no âmbito do CREAS do município de} Arcoverde, Pernambuco

De acordo com o Relatório da Pesquisa Nacional das Medidas Socioeducativas em Meio Aberto, feito pelo Ministério do Desenvolvimento Social (MDS), no ano de 2018, o Brasil possui 117.207 adolescentes cumprindo medidas de liberdade assistida e/ou prestação de serviços à comunidade. Tal número corresponde a $82 \%$ de todas as medidas socioeducativas aplicadas no país. Desse total de jovens, 69.930 cumprem medida de prestação de serviços à comunidade e 84.755 a liberdade assistida ${ }^{3}$ (MDS, 2018). Verifica-se que as medidas socioeducativas de meio aberto abrangem a maioria dos(as) adolescentes que praticaram atos infracionais no país. Entretanto, a temática ainda é pouco abordada no âmbito acadêmico das ciências sociais, ao contrário das medidas de privação de liberdade que, devido à sua complexidade, ganham maior realce.

Abaixo é visto o panorama do tipo de medida por região do país.

\footnotetext{
${ }^{3}$ Importante ressaltar que, nestes dados, um(a) adolescente pode estar cumprindo as duas medidas ao mesmo tempo.
} 
Gráfico 4 - Tipo de medida socioeducativa por região do país

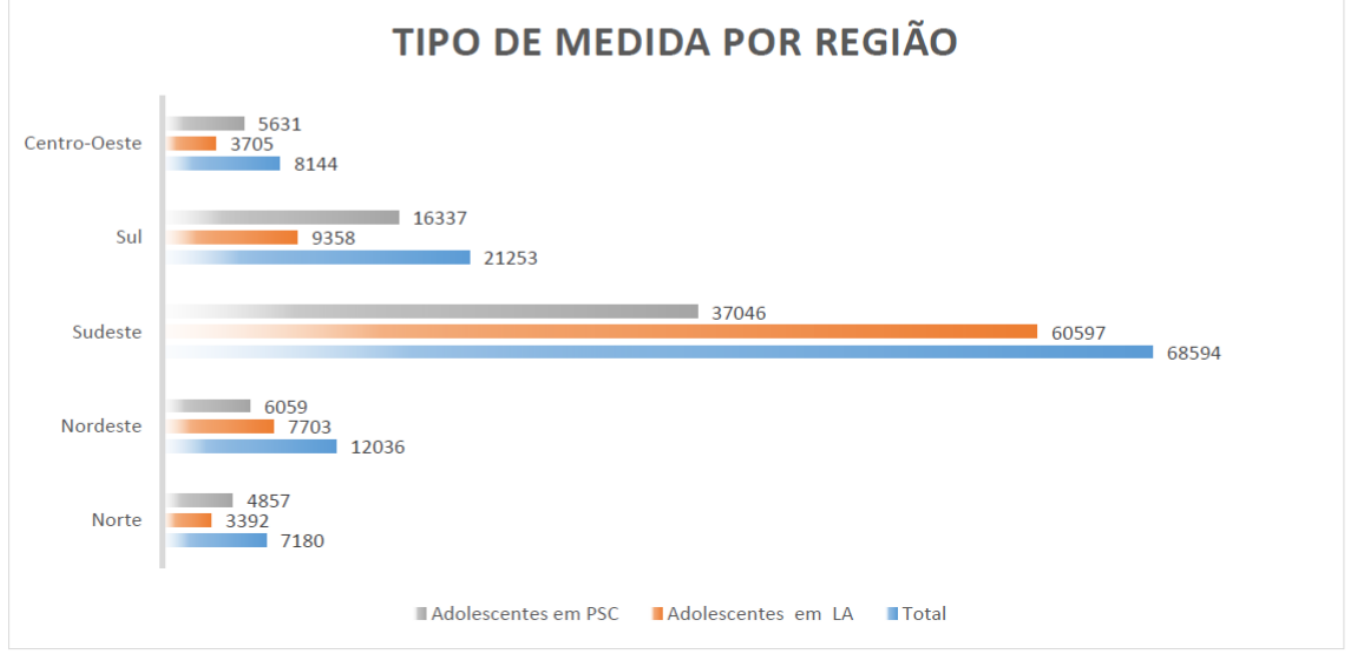

Fonte: Relatório da Pesquisa Nacional das Medidas Socioeducativas em Meio Aberto, 2018.

Com relação aos municípios tem-se o seguinte quadro:

Gráfico 5 - Tipo de medida socioeducativa por porte do município

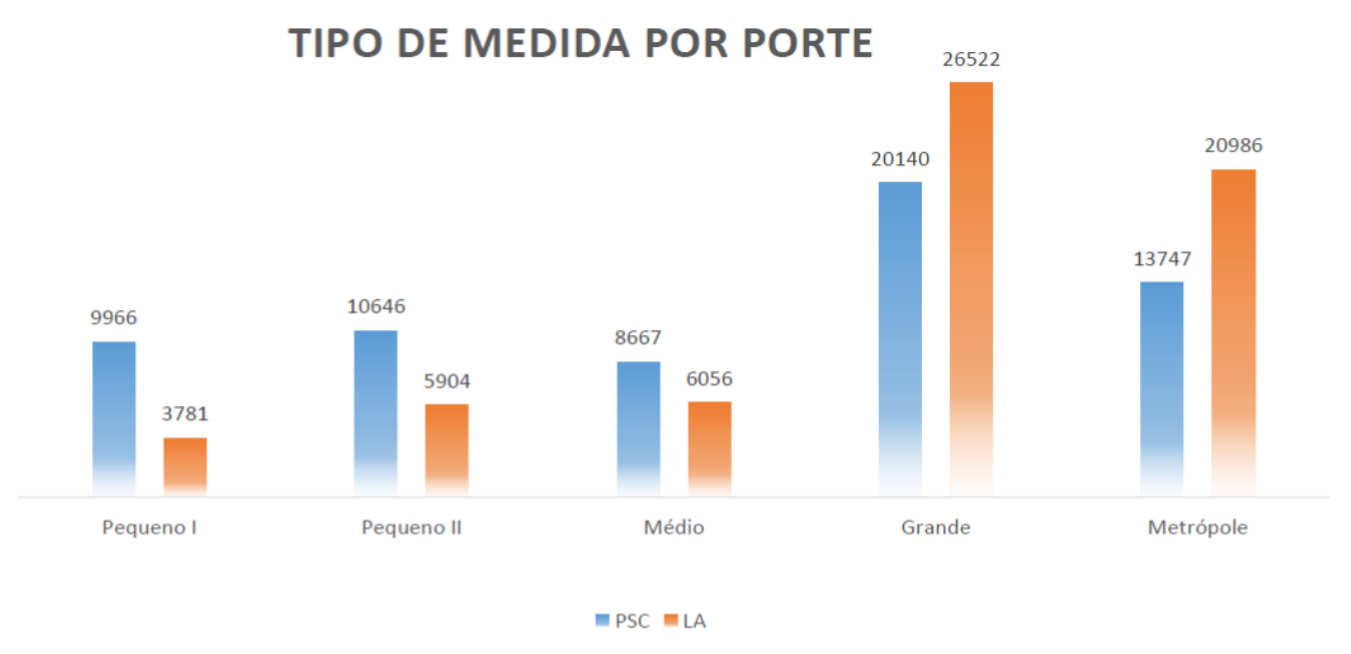

Fonte: Relatório da Pesquisa Nacional das Medidas Socioeducativas em Meio Aberto, 2018.

A partir dos Gráficos 4 e 5 nota-se que as regiões Centro-Oeste, Sul e Norte apresentam predominância de medidas de PSC, enquanto no Sudeste e no Nordeste predominam as medidas de LA. A diferença decorre dos entendimentos diversos do Judiciário de cada região sobre que medida ser aplicada, à gravidade dos atos infracionais, à concentração urbana e ao recurso às substituições das medidas de semiliberdade e internação por liberdade assistida, como transição para o meio aberto (MDS, 2018). Ainda segundo o Relatório Nacional, a concentração de adolescentes cumprindo medidas socioeducativas está na região Sudeste, principalmente no estado de São Paulo, mas também há grande incidência na região Sul, com destaque para o Paraná, e, na região Nordeste, existe uma predominância 
nos estados de Alagoas e Pernambuco. Por outro lado, nos municípios de grande porte e nas metrópoles, é predominante a medida de liberdade assistida em detrimento da medida de prestação de serviços à comunidade.

Ao observar o Gráfico 5, abaixo, existe certa diferença da distribuição/aplicação das medidas socioeducativas quando levado em consideração o tamanho dos municípios. Nos municípios de pequeno e médio porte é recorrente a medida de prestação de serviços à comunidade em relação à medida de liberdade assistida. Sobre os tipos de unidades que ofertam as medidas socioeducativas em meio aberto, o Gráfico 6 demonstra que os atendimentos aos adolescentes ocorrem, em sua maioria, no Centro de Referência Especializado em Assistência Social (CREAS) dos municípios, 36\% dos municípios aplicam as medidas nesta unidade, atendendo cerca de $62 \%$ dos adolescentes.

Gráfico 6 - Unidade de acompanhamento do serviço socioeducativo

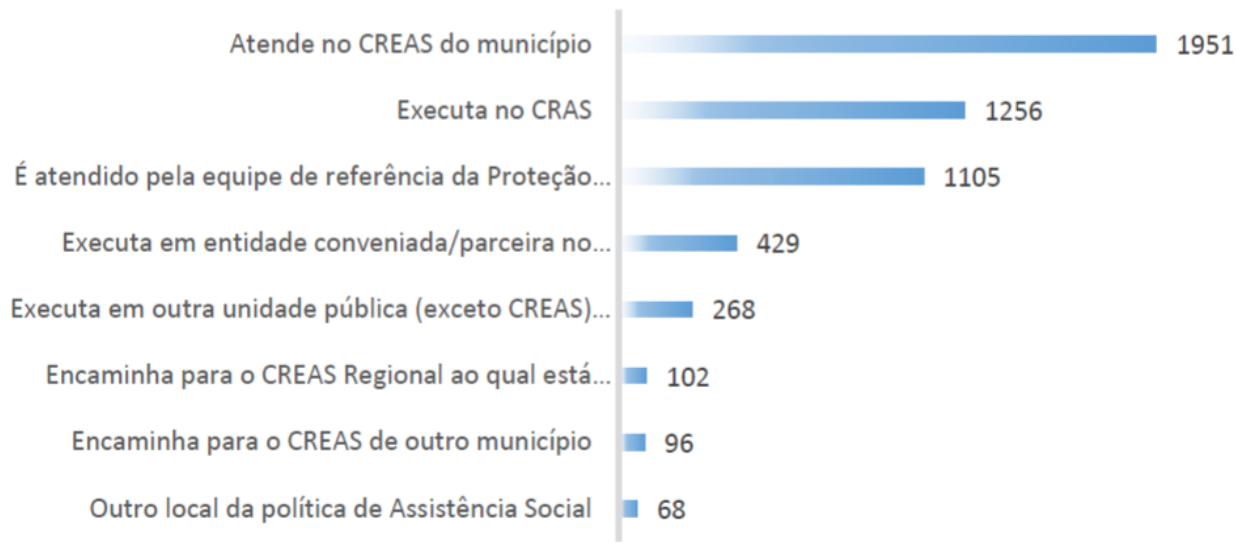

Fonte: Relatório da Pesquisa Nacional das Medidas Socioeducativas em Meio Aberto, 2018.

Todavia, alguns municípios atendem os adolescentes nos Centros de Referência de Assistência Social (CRAS) ou em outros órgãos gestores por ausência de CREAS, por não haver estruturação da Proteção Especial ou por outras questões. A Tipificação dos Serviços Socioassistenciais prevê que o cumprimento das medidas de LA e PSC deve ocorrer somente nos CREAS. Contudo, a Lei do SINASE, que é posterior e mais ampla, não especificou a exclusividade de nenhum órgão, permitindo, assim, que variados órgãos passassem a atender e executar as medidas nos municípios (MDS, 2018).

No município de Arcoverde/PE, objeto deste estudo, as medidas socioeducativas em meio aberto são acompanhadas pelo CREAS. O órgão atende em média 37 adolescentes por ano. As medidas foram distribuídas da seguinte forma: 
Gráfico 7 - Distribuição dos tipos de medidas socioeducativas cumpridas em meio aberto no município de Arcoverde/PE nos anos de 2015 a 2018

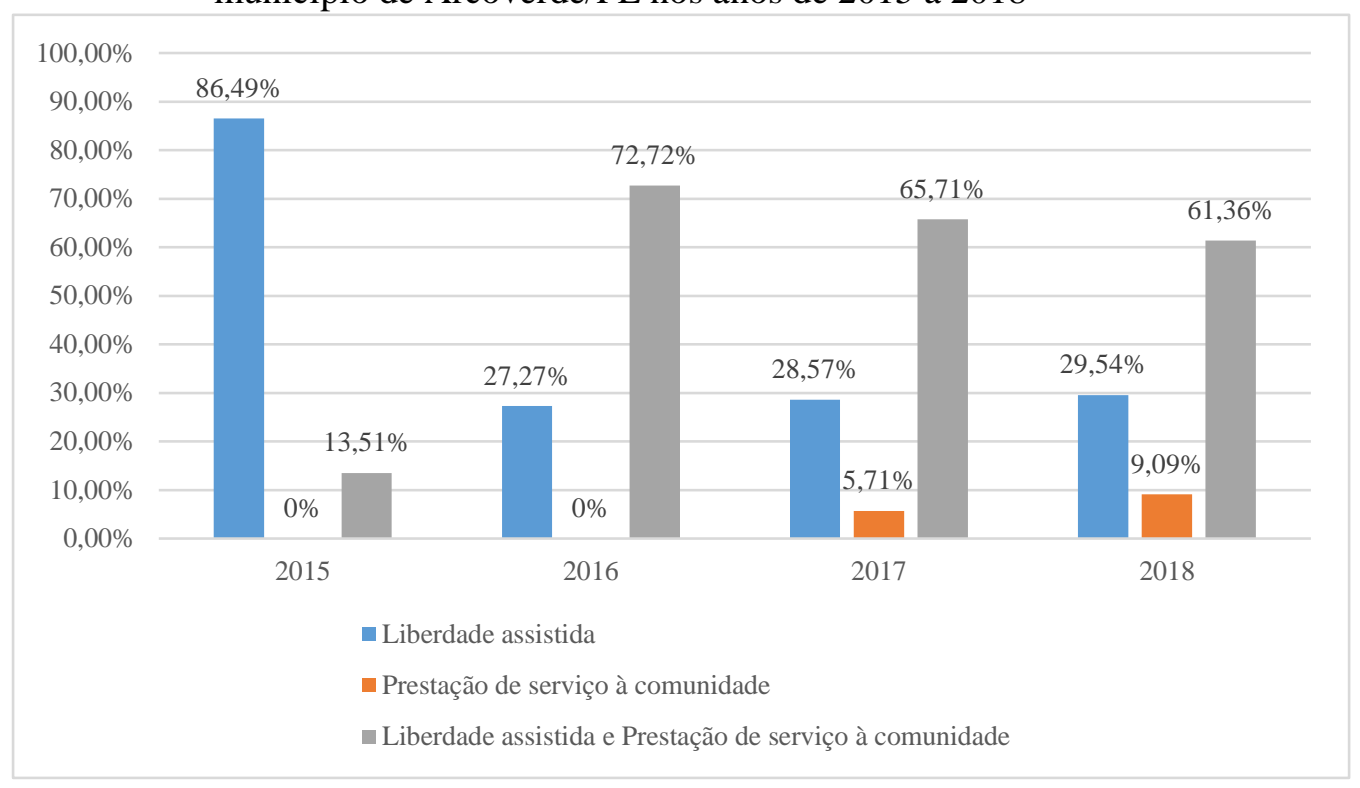

Fonte: Dados coletados pelos autores.

Conforme o Gráfico 7, vê-se que entre os anos de 2015 e 2018 houve uma mudança quanto aos tipos de medidas aplicadas no município. No ano de 2015, a grande maioria dos adolescentes $(86,49 \%)$ cumpria a medida de liberdade assistida, apenas, enquanto o restante $(13,51 \%)$ cumpria as medidas de liberdade assistida e a prestação de serviços à comunidade cumulativamente, não existindo quem cumprisse unicamente a PSC. O ano de 2016 aponta mudanças. A maioria dos adolescentes $(72,72 \%)$ estava cumprindo as medidas LA e PSC simultaneamente, enquanto $27,27 \%$ cumpriam apenas a liberdade assistida, sem haver, ainda, adolescentes cumprindo unicamente a medida de prestação de serviços à comunidade. Nos anos de 2017 e 2018 verifica-se a permanência da constante de adolescentes cumprindo as medidas de LA e PSC juntas, porém, destoando dos anos anteriores, já que parcela significativa de adolescentes também cumpriam a medida de prestação de serviços à comunidade, apenas.

O aumento do número de adolescentes cumprindo a medida de PSC, e esta juntamente com a LA, demonstra que o Judiciário, em suas decisões, após o ano de 2015, ampliou a visão socioeducacional para com os(as) adolescentes. A medida de PSC, ou sua cumulação com a LA, possibilita que reflitam sobre o contexto em que a medida está sendo realizada, compreendendo a prestação de serviços como uma forma de retribuição social, principalmente na cumulação, visto que a LA proporciona um caminho orientador à PSC. Portanto, os serviços que prestarão à comunidade não devem ser ligados a afazeres descontextualizados, 
pois, caso isso ocorra, o propósito socioeducacional do ECA restará perdido (CARDOSO; SILVA, 2018).

\subsection{A execução das medidas em meio aberto no CREAS Arcoverde e os dimensionamentos da socioeducação}

Como já mencionado anteriormente, as medidas socioeducativas em meio aberto devem ser executadas de forma intersetorial, aplicando-se o princípio da incompletude institucional, ou seja, não devem ser dissociadas das demais políticas públicas de interesse comum à efetivação dos direitos desse grupo. Nesse contexto, para que isso aconteça é imprescindível, antes de tudo, a existência do Plano Municipal de Atendimento Socioeducativo. $\mathrm{O}$ atendimento em rede funciona como o instrumento de integral aplicação do conceito de socioeducação.

O Relatório da Pesquisa Nacional das Medidas Socioeducativas em Meio aberto, de 2018, informa que apenas 58\% dos municípios elaboraram seus Planos Municipais de Atendimento Socioeducativo e somente $16 \%$ possuem comissão intersetorial do SINASE. O relatório também indica que apenas $16 \%$ dos municípios possuem equipe técnica exclusiva no serviço de proteção social a adolescentes que cumprem medidas em meio aberto (MDS, 2018).

Em correlação com os dados nacionais, o município de Arcoverde/PE ainda não elaborou o Plano Municipal de Atendimento Socioeducativo e não possui Comissão Intersetorial do SINASE. Quanto à equipe técnica, o CREAS do município é composto pelo seguinte quadro de profissionais: uma coordenadora, uma psicóloga, dois(duas) educadores(as) sociais, dois(duas) assistentes sociais e uma secretária. No entanto, dentre tais servidores(as), os(as) responsáveis pelo acompanhamento das medidas socioeducativas em meio aberto são: os(as) educadores sociais, os(as) assistentes sociais e o(a) psicólogo(a), este(a) que também trabalha no acompanhamento das medidas protetivas.

É traçado a seguir o panorama de como as medidas socioeducativas em meio aberto são executadas no município de Arcoverde/PE:

Após determinar qual (ou quais) medida socioeducativa será cumprida, o(a) juiz da Vara da Infância e da Juventude da comarca expede dois ofícios com o detalhamento da decisão, um é entregue ao(à) adolescente e o outro é encaminhado ao CREAS, através de Oficial de Justiça. O(A) adolescente, ao receber o ofício, tem um prazo de 48 (quarenta e oito) horas para se apresentar no CREAS e, no caso de não se apresentar, será marcada uma audiência de justificação para explicar ao juiz o motivo da ausência. Porém, se o(a) 
adolescente não comparecer a esta audiência de justificação cumprirá uma internação (sanção), na FUNASE, por um período de 30 a 45 dias. Se o(a) adolescente se apresenta no CREAS, primeiramente, é elaborado seu Plano Individual de Atendimento (PIA) pelo(a) educador(a) social, assistente social e o(a) sua responsável familiar, conforme dispõe o art. 53 da Lei do SINASE.

Para o cumprimento da medida de liberdade assistida, após a elaboração do PIA, é agendada a primeira reunião do(a) adolescente no CREAS. As reuniões acontecem uma vez por mês, em grupo, e são conduzidas pelo(a) educador(a) social e o(a) assistente social. Ocorre a criação de dois grupos, um pela manhã e outro à tarde, devido à existência de rivalidades entre os adolescentes. As reuniões duram cerca de uma hora e meia e nelas a equipe do CREAS fala sobre o ECA, direitos e deveres dos(as) adolescentes, da importância de regras e compartilham vídeos com exemplos de vida de outros(as) jovens, refletindo sobre perspectivas de futuro.

Além das reuniões, para que também exista a participação da família e a demonstração de sua importância na vida de cada adolescente, ocorrem reuniões bimestrais, em grupo, com responsáveis familiares. As reuniões são conduzidas pela psicóloga. Em regra, a medida de liberdade assistida tem duração de seis meses, pois, nos termos do art. 42 da Lei do SINASE, deverá ser reavaliada no máximo a cada seis meses.

A respeito do cumprimento da medida de prestação de serviços à comunidade, até o final do ano de 2015, os(as) adolescentes eram encaminhados para o Batalhão da Polícia Militar do município, sem nem ao menos passarem pelo CREAS. Lá realizavam serviços gerais de limpeza. No entanto, desde o ano de 2016, após a decisão que determinava a medida, os(as) adolescentes passaram a ser encaminhados(as) para o CREAS, a fim de serem identificadas suas habilidades e potencialidades para se chegar a um consenso sobre o cumprimento da medida. O CREAS passou a construir parcerias com diversas instituições, escolas, postos de saúde, Fundações, entidades municipais e estaduais. Tais parcerias estão em consonância com o art. 14 da Lei do SINASE, o qual orienta a ligação com esses tipos de entidades. Durante o cumprimento da medida de PSC, a equipe realiza visitas regulares nos locais em questão. Contudo, como já demonstrado no Gráfico 7, é predominante no município o cumprimento das medidas de LA e PSC de forma simultânea. Nestes casos, o(a) adolescente presta os serviços no local designado e comparece às reuniões de acompanhamento no CREAS.

Além das reuniões mensais no CREAS, também são realizadas atividades externas. Os(as) adolescentes são acompanhados(as) pelo(a) educador(a) social e realizam visitas a 
instituições do município, com o intuito de gerar experiências em temáticas variadas. Dentre as instituições está o Centro de Educação e Desenvolvimento Comunitário (CEDEC), reconhecido por sua atuação e assistência social; o projeto socioambiental Casa Verde, da Companhia Pernambucana de Saneamento (COMPESA), o qual promove oficinas e palestras com foco socioambiental; o Grupo de Socorristas Voluntários de Arcoverde (GSVA) e as emissoras de rádio locais. Também são ofertados cursos profissionalizantes no Centro de Inclusão Produtiva do município, na Fundação Terra e em uma escola técnica privada.

Ao término do cumprimento da medida de liberdade assistida e/ou de prestação de serviços à comunidade, a equipe técnica do CREAS elabora um relatório que contém o desempenho do adolescente, opinando pela manutenção, substituição ou suspensão da medida. Este relatório é encaminhado ao(à) juiz(a) da Vara da Infância e da Juventude para análise.

A partir do processo de execução das medidas socioeducativas no âmbito do CREAS é verificada a diminuição da reincidência ao longo dos anos. Vejamos:

Gráfico 8 - Adolescentes reincidentes nas medidas socioeducativas de meio aberto no município de Arcoverde/PE nos anos de 2012 a 2018

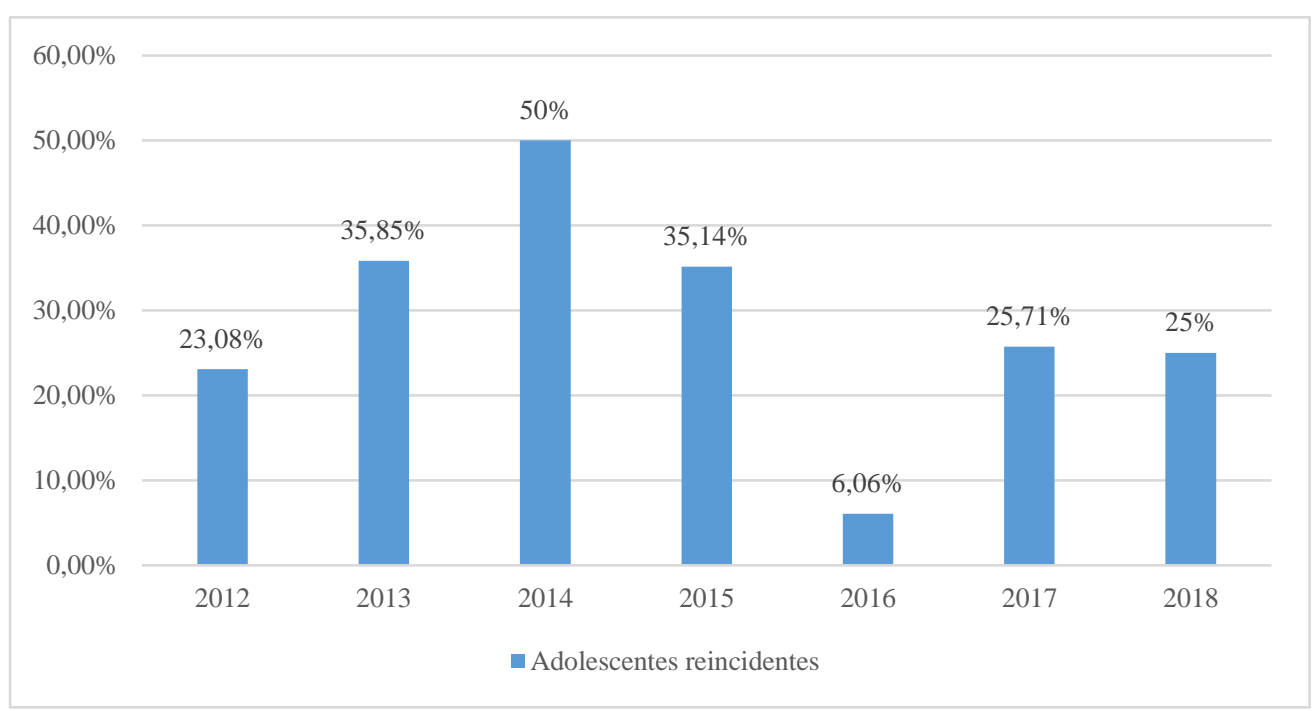

Fonte: Dados coletados pelos autores.

Como pode ser verificado no Gráfico 8, entre 2012 e 2014 há um aumento do índice de reincidência de adolescentes em cumprimento de medidas socioeducativas em meio aberto. De 2015 a 2018 a reincidência diminui, tendo em 2016 o menor índice do período analisado. A diminuição de adolescentes reincidentes coincide com a mudança da equipe técnica do CREAS, ocorrida no ano de 2015, a qual, como dito anteriormente, repensou a execução das medidas. 
Macedo (2018) explica que o conceito de reincidência não deve ser entendido como o mero comportamento repetitivo em um ato infracional, pois este entendimento superficial encobre elementos que influenciam o fenômeno, como a não efetivação de direitos garantidos em lei. A garantia de direitos, o atendimento socioeducativo de caráter pedagógico e intersetorialidade vistam no âmbito do CREAS do município de Arcoverde são aspectos que contribuem, mesmo que timidamente, para diminuir os índices de reincidência de adolescentes.

Portanto, como pode ser verificado, a execução das medidas socioeducativas em meio aberto no município de Arcoverde, Pernambuco, tem características pedagógicas constatadas na realização de reuniões mensais e atividades educativas externas, mas possui um tímido atendimento intersetorial, pois ainda existem muitos outros órgãos municipais que poderiam receber os(as) adolescentes.

\section{Considerações finais}

O presente estudo buscou analisar os dimensionamentos da socioeducação na execução das medidas socioeducativas em meio aberto (LA e PSC) do município de Arcoverde/PE, para tanto, foi ressaltado o conceito de socioeducação presente na doutrina.

Entre os objetivos específicos deste trabalho verificou-se que foi Antônio Carlos Gomes da Costa, pedagogo e um dos redatores do ECA, quem cunhou o termo 'socioeducação', a fim de evidenciar o caráter educativo das medidas. Para ele, o objetivo da socioeducação é preparar o adolescente para o convívio social, oferecendo oportunidades de desenvolvimento pessoal e social, a partir de diversas etapas interligadas. Dessa forma, a socioeducação seria o conjunto de práticas voltadas para a realização integral de direitos previstos em lei.

Constatou-se que, para que o viés pedagógico seja predominante, faz-se necessário compreender as bases teóricas da socioeducação e as metodologias interligadas ao atendimento socioeducativo. De acordo com o SINASE, o atendimento socioeducativo também precisa ser realizado de forma intersetorial com uma articulação dos órgãos municipais que têm interesses em comum na efetivação dos direitos desse grupo. Todavia, para a organização e sistematização do atendimento é necessária a elaboração do Plano Municipal de Atendimento Socioeducativo e a atuação da Comissão Intersetorial do SINASE, que subsidiarão o desenvolvimento do Plano Individual de Atendimento dos(as) adolescentes. Dentre as dificuldades para a implementação de práticas socioeducativas intersetoriais em 
meio aberto, constatou-se a inexistência do Plano Municipal de Atendimento Socioeducativo e das Comissões Intersetoriais do SINASE no universo estudado.

Os dados de âmbito nacional e a nível do município de Arcoverde/PE, sobre os marcadores sociais dos adolescentes e a respeito das medidas socioeducativas de meio aberto, proporcionaram uma visão comparativa. Foi observada a predominância do público masculino no atendimento socioeducativo, tanto a nível nacional como no município de Arcoverde/PE, e verificou-se, também, o aumento das adolescentes em cumprimento de medidas em meio aberto do município, o baixo índice de adolescentes frequentando a escola e a utilização de drogas.

A nível nacional, que a grande maioria dos adolescentes que cometeram atos infracionais cumprem medidas socioeducativas de meio aberto. A medida de liberdade assistida tem predominância nas regiões Sudeste e Nordeste, mas no município de Arcoverde, Pernambuco, viu-se a predominância do cumprimento cumulativo das medidas de LA e PSC.

Após a coleta de dados sobre a execução das medidas socioeducativas em meio aberto do município de Arcoverde/PE, constatou-se que o CREAS realiza ações pedagógicas, organiza atividades educativas externas, incentiva o reingresso à escola e oferece a realização de cursos profissionalizantes em entidades públicas e privadas. Numa visão socioeducativa, atuação do CREAS do município é importante para a diminuição dos índices de reincidência. Entretanto, o município possui outros órgãos municipais que poderiam atuar no atendimento socioeducativo, a fim de existir o real atendimento em rede. Contudo, o município de Arcoverde ainda não elaborou seu Plano Municipal de Atendimento Socioeducativo e não possui Comissão Intersetorial do SINASE, fatos que dificultam a aplicação plena conceito de socioeducação na execução das medidas. É válido ressaltar que a elaboração do plano e a criação da comissão intersetorial não depende apenas de CREAS, mas sim de um amplo trabalho e discussão, que devem envolver vários setores e órgãos do município.

\section{Referências}

ANDRADE, Paulo Gonçalves de; CARDOSO, Fernando da Silva. Marcadores de vulnerabilidade presentes no trajeto social de jovens em cumprimento de liberdade assistida em decorrência do tráfico de drogas. Revista Direitos Sociais E Políticas Públicas UNIFAFIBE, v. 6, p. 445-485, 2018. DOI: http://dx.doi.org/10.25245/rdspp.v6i2.466.

ARANZEDO, Alexandre Cardoso. "Meninas": os conflitos com a lei e as representações das medidas socioeducativas. Psicologia e Saber Social - UERJ, v. 4, n. 2, p. 265 - 276. 2015. ISSN 2238-779X. Disponível em: http://www.e-publicacoes.uerj.br/index.php/psisabersocial/article/view/16413. Acesso em: 15 jun. 2019. 
BARBOSA, Janilson Pinheiro. Pedagogia socioeducativa - Repensando a socioeducação: um encontro entre educação libertadora e justiça restaurativa. 2013. 237 f. Tese (Doutorado em Educação), Universidade do Vale do Rio dos Sinos, São Leopoldo.

BRASIL. Lei no 8.069, de 13 de julho de 1990. Estatuto da Criança e do Adolescente ECA. Diário Oficial [da] República Federativa do Brasil. Brasília, 16 de julho de 1990.

BRASIL. Lei $\mathbf{n}^{\circ}$ 12.594, de 18 de janeiro de 2012. Sistema Nacional de Atendimento Socioeducativo - SINASE. Diário Oficial [da] República Federativa do Brasil. Brasília, 19 de janeiro de 2012.

BRASIL. Resolução n ${ }^{\circ}$ 106, Secretaria Especial dos Direitos Humanos (SDH) - Conselho Nacional dos Direitos da Criança e Adolescente. Sistema Nacional de Atendimento Socioeducativo - SINASE. Brasília: Presidência da República, 2006.

BRITO, Leila M. T. Liberdade Assistida no Horizonte da Doutrina de Proteção Integral. Psicologia: Teoria e Pesquisa, Rio de Janeiro, v. 23, n. 2, p. 133-138, abr./jun. 2007.

CARDOSO, Fernando da Silva; SILVA, Maria Alba da. Efetivação de direitos de crianças e adolescentes em um município do agreste de Pernambuco: um estudo empírico. Revista Eletrônica de Direito do Centro Universitário Newton Paiva, Belo Horizonte, n. 35, p. 88108, maio/ago. 2018. Disponível em: http://blog.newtonpaiva.br/direito/wpcontent/uploads/2018/12/DIR35-06.pdf. Acesso em: 19 mar. 2018.

COSTA, Antonio Carlos Gomes da (Coord.). Socioeducação: estrutura e Funcionamento da Comunidade Educativa. Brasília: Secretaria Especial dos Direitos Humanos, 2006.

COSTA, Cândida da. Dimensões da medida socioeducativa: entre o sancionatório e o pedagógico. Revista Textos e Contextos - PUC/RS, v. 14, n. 1, p.62 - 73, jan./jun. 2015. ISSN 1677-9509. Disponível em: http://revistaseletronicas.pucrs.br/ojs/index.php/fass/article/view/16858. Acesso em: 29 mai. 2019.

GERHARDT, Tatiana Engel; SILVEIRA, Denise Tolfo (Org.). Métodos de pesquisa; coordenado pela Universidade Aberta do Brasil - UAB/UFRGS e pelo Curso de Graduação Tecnológica - Planejamento e Gestão para o Desenvolvimento Rural da SEAD/UFRGS. 1. ed. Porto Alegre: Editora da UFRGS, 2009.

JULIÃO, Elionaldo; OLIVEIRA, Vivian; GODOI, Renan. Sistema de Garantia de Direitos: Novas concepções para o atendimento socioeducativo. Revista Pedagogia Social UFF, v. 1, n. 01, june. 2017. Disponível em: http://www.revistadepedagogiasocial.uff.br/index.php/revista/article/view/40. Acesso em: 6 jul. 2018.

LAKATOS, Eva Maria; MARCONI, Marina de Andrade. Fundamentos de metodologia científica. 5. ed. São Paulo: Atlas, 2003.

MACEDO, Marcos. A fabricação da reincidência do ato infracional pelo sistema socioeducativo: adolescentes privados de liberdade, de educação e de profissionalização. 2018. 234 f. Tese (Doutorado em Educação), Universidade Federal Fluminense, Niterói. 
MACHADO, Isadora Vier. Adolescentes institucionalizadas: um estudo sobre proteção integral e gênero no Centro de Socioeducação da região de Ponta Grossa-PR. 2010. 192 f. Dissertação (Mestrado em Direito) - Universidade Federal de Santa Catarina, Florianópolis.

Ministério do Desenvolvimento Social e Agrário - MDS. Caderno de Orientações Técnicas: Serviço de Medidas Socioeducativas em Meio Aberto. Secretaria Nacional de Assistência Social. Brasília, Distrito Federal: 2016. Disponível em: https://www.mds.gov.br/webarquivos/publicacao/assistencia_social/Cadernos/caderno_MSE_ 0712.pdf. Acesso em: 16 jun. 2019.

Ministério do Desenvolvimento Social - MDS. Relatório da Pesquisa Nacional das Medidas Socioeducativas em Meio Aberto. Secretaria Nacional de Assistência Social. Brasília, Distrito Federal: 2018. Disponível em: http://www.mds.gov.br/webarquivos/publicacao/assistencia_social/relatorios/Medidas_Sociod ucativas_em_Meio_Aberto.pdf. Acesso em: 16 jun. 2019.

NEVES, Carla Malinowski. A intersetorialidade no sistema nacional de atendimento socioeducativo: experiências no município de Porto Alegre-RS. 2014. 167 f. Dissertação (Mestrado em Psicologia Social e Institucional) - Universidade Federa do Rio Grande do Sul, Porto Alegre.

PAES, Paulo C. Duarte; AMORIM, Sandra M. Francisco (Org.). Formação continuada de socioeducadores, caderno 1. Campo Grande, MS: Programa Escola de Conselhos, 2008.

PAES, Paulo C. Duarte; AMORIM, Sandra M. Francisco; PEDROSSIAN, Dulce R. dos Santos (orgs.). Formação continuada de socioeducadores, caderno 2 - Campo Grande, MS: Ed. UFMS, 2010.

PAES, Paulo C. Duarte; ADIMARI, Maria Fernandes; COSTA, Ricardo Peres (Org.). Socioeducação e intersetorialidade: formação continuada de socioeducadores: [caderno 6] Campo Grande, MS: Ed. UFMS, 2015.

RANIERE, Édio. A invenção das medidas socioeducativas. 2014. 196 f. Tese (Doutorado em Psicologia Social e Institucional) - Universidade Federal do Rio Grande do Sul, Porto Alegre.

VIANNA, Carlos Eduardo Souza. Evolução histórica do conceito de educação e os objetivos constitucionais da educação brasileira. Revista Janus - UNIFATEA, v. 3, n. 04, 2006. Disponível em: http://publicacoes.fatea.br/index.php/janus/issue/view/4. Acesso em: 7 jul. 2018.

VIDAL, Alex da Silva. Adolescentes em medida socioeducativa: um estudo sobre estigma. 2014. 160 f. Dissertação (Mestrado em Educação), Universidade Federal do Rio Grande do Sul, Porto Alegre.

ZANELLA, Maria Nilvane. Bases teóricas da socioeducação: análise das práticas de intervenção e metodologias de atendimento do adolescente em situação de conflito com a lei. 2011. 210 f. Dissertação (Mestrado em Adolescente em conflito com a lei) - Universidade Bandeirante de São Paulo, São Paulo. 